\title{
REMOTE SENSING-BASED EXTRACTION OF SUMMER SNOWLINE AND ANALYSIS OF ITS VARIATION CHARACTERISTICS IN XINJIANG, CHINA
}

\author{
HU, L. Q. ${ }^{2}-$ ZHANG, L. C. ${ }^{1 *}-$ LI, S. ${ }^{3}-$ LI, H. J. ${ }^{4}-$ ZhANG, T. W. ${ }^{3}-$ HOU, X. G. ${ }^{2}$ \\ ${ }^{I}$ Xinjiang Climate Center, Urumqi 830002, China \\ ${ }^{2}$ Xinjiang Meteorological Service Center, Urumqi 830002, China \\ ${ }^{3}$ Institute of Desert Meteorology, China Meteorological Administration, Urumqi 830002, China \\ ${ }^{4}$ College of Geography Science and Tourism, Xinjiang Normal University \\ Urumqi, Xinjiang 830054, China \\ *Corresponding author \\ e-mail:524480929@qq.com
}

(Received $31^{\text {st }}$ May 2018; accepted $2^{\text {nd }}$ Aug 2018)

\begin{abstract}
As a zero-balance line, lying between snow-covered and snow-free land areas, the snowline reflects the melting and retreating of snow and ice, which also mirrors the basic situation of climate and environment on mountain plateaus and in polar regions where there is a lack of ground meteorological stations. Thus, it is important to accurately extract and assess the distribution characteristics of the snow-line from hydrological, climatological, and geological aspects. This study extracted summer snowline data from the Xinjiang region in China using the snow cover duration ratio (SCDR) method with MODIS daily snow cover products (MOD10A1 and MYD10A1), IMS and Landsat data, and temperature and precipitation observations from 2001-2015. The variation and distribution characteristics of the summer snowline elevation were analyzed comparatively for the Xinjiang region and its different subareas. The results showed that snowline elevation data extracted using the SCDR method passed the accuracy test and therefore, it was considered suitable for the Xinjiang region. During 2001-2015, the average snowline elevation remained at about $3950 \mathrm{~m}$ within a $250-\mathrm{m}$ range of fluctuation. However, linear trend analysis revealed an annual increasing trend of average snowline elevation with a tendency rate of $160.38 \mathrm{~m} / \mathrm{decade}$. The minimum snowline elevation exhibited a fluctuating upward trend, whereas the maximum snowline elevation showed a slight downward trend. Comparative analysis of snowline elevation in different areas of the Xinjiang region revealed a fluctuating upward trend in the Kunlun, Tianshan, and Altai Mountains. The Altai Mountains showed the most stable variation of snowline elevation, followed by the Kunlun Mountains and then the Tianshan Mountains. Spatially, the distribution of snowline elevation in the Xinjiang region was characterized by a decline from south to north with longitudinal zonation.
\end{abstract}

Keywords: Xinjiang, summer snowline, snow cover duration ratio method

\section{Introduction}

Traditionally, snowline elevation has been determined mainly by artificial means (Jiang, 1987; Wang et al., 2003; Hangel and Maurer, 2011; Liu et al., 2015). For example, ground stations for field observations would be established and devices used to perform the measurements. However, such methods are time consuming, costly, and provide only limited numbers of samples (Li et al., 2013). Subsequently, the Hess method was introduced to measure snowline altitude (ELAh) indirectly (Deng et al., 2006; Wang et al., 2010; Nie et al., 2013). Although this method overcame some of the disadvantages of direct measurement, the ELAh measured was primarily confined to large glaciers. Additionally, this method could only acquire static ELAh and it could not 
rapidly reflect the state of snowline variation. With the development of remote sensing technology, McFadden et al. (2011) identified snowline spatial distribution using Landsat TM and ETM+ satellite images. Furthermore, based on ASTEG-DEM, this research group also extracted the range of ELAh in the area of glacier coverage in the Peruvian Andes. Using LISS III and AWIFS data from the United States, Brahmbhatt et al. (2012) calculated the glacier mass balance and extracted the glacier snowline in the Warwan and Bhut Basins in northern India during 2005-2007. Moreover, Xiao et al. (2010) introduced an analysis of water flow path into the extraction of snowline information based on remote sensing data.

Complex topography makes access difficult to mountainous glacier areas, and therefore, to meet the requirements for macroscopic, comprehensive, and rapid monitoring of snowline variation, remote sensing-based snowline extraction methods remain the focus of future development. Several different types of snowline have been proposed as a consequence of snowline research (Jiang et al., 2004), e.g., the theoretical snowline, local snowline, glacier equilibrium line, permanent snowline, and seasonal snowline. Presently, no research is available in the literature regarding the snowline in the Xinjiang region of China. Recently, the area of snow cover in the Xinjiang region has shown increasing variability with a downward trend (Sa et al., 2013). From the perspective of seasonal variation, a study of summer snowline is most informative regarding snow cover stability and snow water resources. Therefore, in this study of the Xinjiang region, we adopted the term snowline to mean the summer snowline. Using MODIS daily snow cover products (MOD10A1 and MYD10A1) after cloud removal for 2001-2015, we extracted snowline data using the snow cover duration ratio (SCDR) method, and we analyzed the dynamic variation characteristics of snowline elevation.

\section{Materials and methods}

\section{Study area}

Xinjiang is located in the center of the Eurasian continent $\left(33^{\circ} 86^{\prime}-48^{\circ} 50^{\prime} \mathrm{N}, 73^{\circ} 18^{\prime}-\right.$ 96 $69^{\circ} \mathrm{E}$ ) (Fig. 1). It is part of China's northwest frontier and it covers an area of $1,664,900 \mathrm{~km}^{2}$, accounting for $1 / 6$ of the total land area of China (Sa et al., 2013). The topography can be described broadly as two basins between three mountain ranges. To the south are the Kunlun Mountains, which extend eastward from Pamirs, bordering the Tarim and Qaidam deserts. They have a warm temperate climate with little precipitation; however, with increasing elevation, the warm temperate climate shifts to alpine desert and the amount of precipitation increases accordingly. To the north are the Altai Mountains, which have a continental climate with warm and rainy summers and cold winters. While there is little snow in the valleys, heavy snowfall occurs in the high mountains. The Tianshan Mountains cross central Xinjiang, dividing the region into two parts. The northern slopes of the Tianshan Mountains have a humid to semiarid climate, with an average annual temperature of $0.9^{\circ} \mathrm{C}$ and average annual precipitation of $450-$ $800 \mathrm{~mm}$ (Zhang et al., 2015b). The foothills of the southern slopes of the Tianshan Mountains extend southward and connect with the Tarim Basin. Because of the influence of the Tarim Basin desert, the southern slopes have higher temperatures than the northern slopes and they receive little precipitation.

Considering the Xinjiang region as an entity, it is far from the sea and it is surrounded by high mountains. It has a typical temperate continental arid climate, with large variation of temperature, long duration of sunshine hours (average annual 
sunshine duration: $2500-3500 \mathrm{~h}$ ), and dry air. The average annual precipitation is $\sim 150 \mathrm{~mm}$, but this varies considerably in the different subareas. The average annual surface water resources of the Xinjiang region are $789 \times 108 \mathrm{~m}^{3}$, accounting for only $3 \%$ of China's total surface water resources, and in the ranking of water production per unit area in China, Xinjiang is third from bottom (Gao et al., 2010). For a province covering $1 / 6$ of China's total land area, this shortage of water resources is particularly serious (Lu et al., 2007). However, the Xinjiang region has abundant snow cover resources that account for $\sim 1 / 3$ of the total snow cover in China (Wang and Che, 2012). Snow cover water resources provide a lifeline to the arid areas of the Xinjiang region; where there is snow cover on the mountains, there is often an associated oasis development on the piedmont plain. In recent years, the reserves of snow and ice in this region have begun to decrease as temperatures have risen. Furthermore, the snowline elevation has become increasingly unstable, and both the regulation capability and the storage capacity of the solid reservoirs in the mountains have deteriorated (Lu et al., 2007). Therefore, the study of the dynamic variation of snowline in this region is of great significance to the protection and utilization of local water resources and ecological construction.

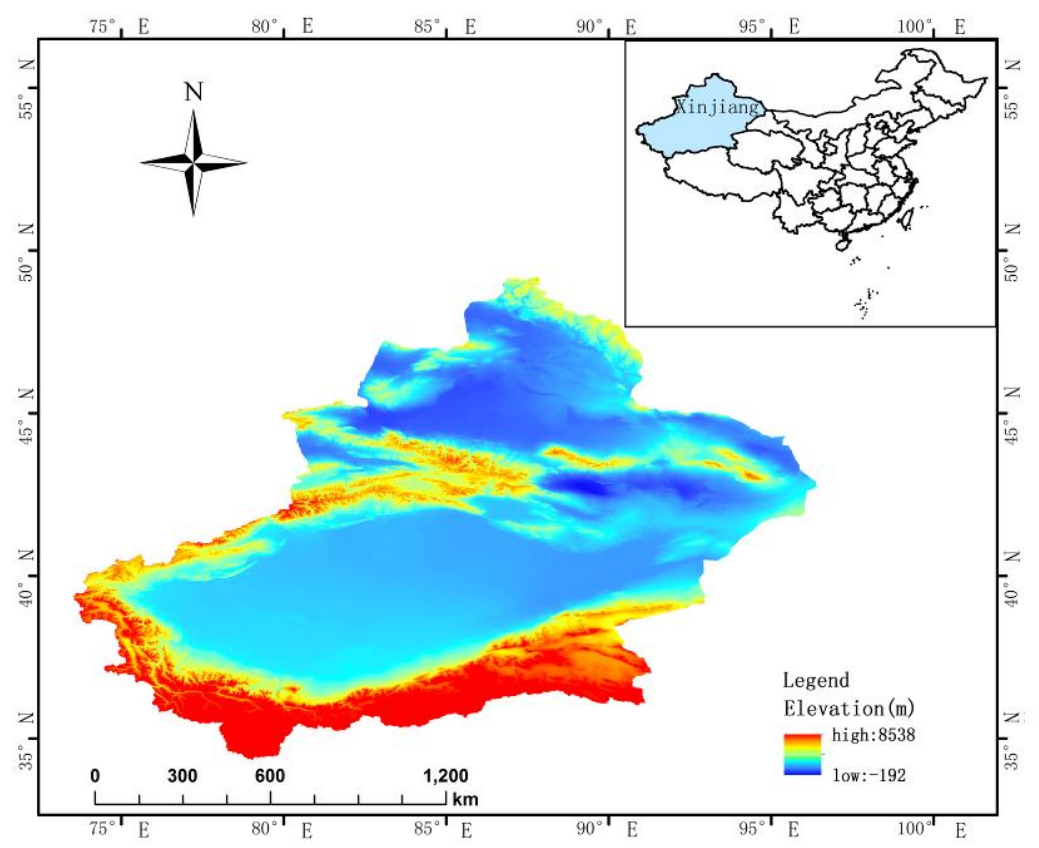

Figure 1. Location of the study area

\section{Study data}

The data used in this study comprised the following:

(1) MODIS daily snow cover products (MOD10A1 and MYD10A1) covering the Xinjiang region were acquired for 2001-2015 from the NASA Data Center, and 4-km IMS data for 2001-2015 were acquired from the NSIDC website. Cloud removal was accomplished using a combination of temporal and spatial filtering on the MOD10A1 and MYD10A1 data, with the IMS data as reference. Thus, the snowline elevation in the study area was extracted for 2001-2015. 
(2) Cloudless 30-m Landsat data of the Xinjiang region for June-August of 2005, 2010, 2014, and 2015 (downloaded from the official USGS website). These data were used as the "true value" to determine the threshold for snowline extraction when using the SCDR method, and to evaluate the accuracy of the extracted snowline elevation.

(3) SRTM DEM data (derived from the International Scientific Data Services Platform, 90-m resolution). These data were used for extracting snowline elevation within the study area.

\section{Study methods}

\section{(1) SCDR method}

In this study, we extracted snowline elevation within the study area using the SCDR method. After cloud removal, MODIS daily snow cover products were used to calculate the probability of snow cover occurrence within specific pixels on the study date. Snowline elevation was then extracted at different probabilities and the 30-m Landsat data were used as the "true value" for error analysis. The probability of snow cover occurrence with the minimum error was taken as the threshold for snowline extraction. The extraction of snowlines using this threshold was regarded as the SCDR method (Zhang et al., 2015a).

\section{(2) Statistical methods}

1. Statistical methods were used to calculate the daily snow cover area within the study area and to determine the range of the study date.

We used the MOD10A1/MYD10A1 snow cover product data for 2001-2015 to calculate the daily snow cover area for June-August of each studied year. The data of minimum snow cover area in each year was obtained, based on which the date range of the minimum snow cover area over the past 15 years was obtained. This range was determined as the study date. Given the vast area of the Xinjiang region, to be able extract the snowline using the SCDR method with greater accuracy, we divided the study area into three parts for the statistical analysis: the Tianshan Mountains, Altai Mountains, and Kunlun Mountains.

2. Statistical methods were used in two schemes to evaluate the accuracy of the extracted snowline.

The first scheme examined the accuracy difference of planar snow cover area. Highresolution $(30 \mathrm{~m})$ Landsat satellite images were used to evaluate the $500-\mathrm{m}$ MOD10A1/MYD10A1 snow cover area image based on the Kappa coefficient (Eq. 1). Given the large difference in the spatial resolutions of the two image types, we counted the number of pixels at 500-m resolution in the area extracted by the Landsat satellite snow cover image after the extraction of the snow cover area by visual interpretation. This was performed to keep the pixel size consistent for calculation of the Kappa coefficient:

$$
K=\left(\boldsymbol{P}_{o}-\boldsymbol{P}_{c}\right) /\left(1-\boldsymbol{p}_{c}\right)
$$

where Po is the observed consistency rate and $\mathrm{Pc}$ is the expected consistency rate. Here, $\mathrm{Pc}=(\mathrm{a} 1 \times \mathrm{b} 1+\mathrm{ao} \times \mathrm{bo})$ and $\mathrm{Po}=\mathrm{s} / \mathrm{n}$, where $\mathrm{n}$ is the total number of pixels in the image, a1 and ao represent the number of pixels with snow cover in the remote sensing image representing the actual snow cover conditions on the ground and the number of 
remaining pixels, respectively, b1 and bo represent the number of pixels with snow cover in the validation image and the number of remaining pixels, respectively, and $s$ is the number of pixels with equal values in the corresponding raster of the two images.

The second scheme obtained the snowline elevation extracted from the Landsat satellite imagery as the "true value" through visual interpretation. The accuracy of snowlines extracted using the SCDR method was evaluated through calculation of the mean error $(\mathrm{Pa})$, positive and negative errors $(\mathrm{Pc}$ and $\mathrm{Pb})$, mean absolute error $(\mathrm{Pd})$, and root mean square error (RMSE) (Eqs. 2-6) between the snowline elevation extracted using the SCDR method and the "true value," as well as the correlation between the above two factors (Yu et al., 2009; Zhang et al., 2013).

$$
\begin{gathered}
P a=\frac{1}{n} \sum_{i=1}^{n}\left(\hat{\left.y_{i}-y_{i}\right)}\right. \\
P c=\frac{1}{r_{k=1}} \sum_{k=1}^{r}\left(y_{k}-\hat{y_{k}}\right)\left(y_{k}>\hat{y_{k}}\right) \\
P b=\frac{1}{m} \sum_{j=1}^{m}\left(y_{j}-\hat{y_{j}}\right)\left(y_{j}<\hat{y_{j}}\right) \\
P d=\frac{1}{n_{i=1}^{n}\left(\left|y_{i}-\mathrm{y}_{i}\right|\right)} \\
R M S E=\sqrt{\frac{\sum_{i=n}^{n}\left(Z_{a i}-Z_{e i}\right)^{2}}{n}}
\end{gathered}
$$

where $y_{i}, y_{j}, y_{k}$, and $\hat{y}_{i}, \hat{y}_{j}, \hat{y}_{k}$ are the true values and their corresponding snowline elevations to be validated, respectively; $\mathrm{n}, \mathrm{m}$, and $\mathrm{r}$ are the total number of samples, number of samples with a measured value lower than the estimated value, and the number of samples with a measured value higher than the estimated value, respectively; $Z_{a i}$ is the true value of the $\mathrm{i}$-th sample point; $Z_{\mathrm{e} i}$ is the estimated value.

\section{(3) Linear trend method}

The linear trend method was used to calculate the trend of snowline variation and to establish the linear regression equation (Eq. 7) between $y_{t}$ and time $t$ :

$$
y_{t}=a+b t
$$

Where $a$ is the regression constant and $b$ is the regression coefficient, i.e., the variation trend; when $b$ is higher (lower) than zero, it indicates an upward (downward) trend. Here, $b \times 10$ (unit: $\mathrm{m} / \mathrm{decade}$ ) is the tendency rate of the snowline (Tang et al., 2012). 


\section{Results and discussion}

\section{Determination of study dates}

Figure 2 shows the dates of minimum snow cover area in the Tianshan, Kunlun, and Altai mountains for each year. To reduce statistical error, we removed the values at two endpoints of anomalies. The results showed that day 206 was the earliest date of minimum snow cover area in the Tianshan Mountains, whereas the corresponding date was day 203 and 216 in the Kunlun and Altai mountains, respectively. The latest date of minimum snow cover area was day 236 in both the Tianshan and Kunlun mountains, whereas it was day 239 in the Altai Mountains. Based on the above, we obtained the study dates for the three major mountain areas of the Xinjiang region: July 25-August 24 (days 206-236) of each year in the Tianshan Mountains (total: 31 days); July 22August 24 (days 203-236) of each year in the Kunlun Mountains (total: 34 days); and August 4-August 27 (days 216-239) of each year in the Altai Mountains (total: 24 days).

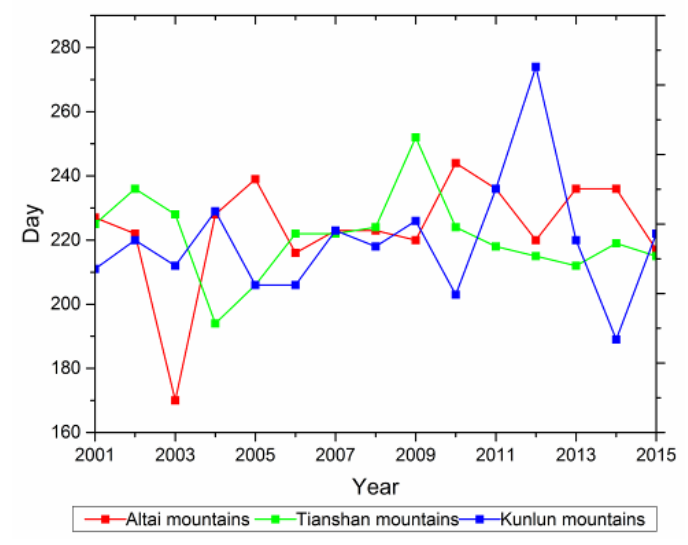

Figure 2. Dates of minimum snow cover area in three mountain areas of the Xinjiang region for each year

\subsection{Snowline extraction in the Xinjiang region}

\section{Threshold determination for the SCDR method}

After cloud removal, we overlaid the MOD10A1/MYD10A1 snow cover product data from the Tianshan, Kunlun, and Altai mountains for the study dates of 2005, 2010, and 2014, respectively (Fig. 3). Then, we calculated the probability of snow cover occurrence in specific pixels within 31 days (Tianshan Mountains), 34 days (Kunlun Mountains), and 24 days (Altai Mountains). In the Tianshan Mountains, we extracted snowline elevation with $3.2 \%, 6.4 \%, 9.6 \%$, and up to $100.0 \%$ probability of snow cover occurrence. In the Kunlun Mountains, we extracted snowline elevation with $2.9 \%$, $5.9 \%, 8.8 \%$, and up to $100.0 \%$ probability of snow cover occurrence. In the Altai Mountains, we extracted snowline elevation with $4.2 \%, 8.3 \%, 12.5 \%$, and up to $100.0 \%$ probability of snow cover occurrence. Then, 30-m Landsat data were used as the "true value" for error analysis. The smaller the difference, the smaller the error, and the probability of snow cover occurrence with the smallest error was determined as the minimum error ratio. Based on the minimum error ratio, we extracted the snowline threshold using the SCDR method when overlaying data for 31, 34, and 24 days in the 
Tianshan, Kunlun, and Altai mountains, respectively. Figure 4 shows the error curves of different ratios in 2005, 2010, and 2014. The minimum error ratios for the Tianshan Mountains were $83.2 \%, 70.4 \%$, and $70.4 \%$; for the Kunlun Mountains, they were $67.7 \%, 79.4 \%$, and $85.3 \%$, and for the Altai Mountains, they were 83.3\%, 83.3\%, and $87.5 \%$. The average of the minimum error ratios of the three years was obtained as the threshold for the SCDR method when overlaying data for 31, 34, and 24 days in the Tianshan, Kunlun, and Altai mountains, respectively. In the Tianshan Mountains, the average ratio was estimated to be $74.7 \%$, closest to the true ratio of $74.2 \%$, i.e., the lower edge of snow cover that appeared in each pixel for 23 days was taken as the snowline in the Tianshan Mountains. In the Kunlun Mountains, the average ratio was $77.5 \%$, closest to the true ratio of $76.5 \%$, i.e., the lower edge of snow cover that appeared in each pixel for 26 days was taken as the snowline in the Kunlun Mountains. In the Altai Mountains, the average ratio was $84.7 \%$, closest to the true ratio of $83.3 \%$, i.e., the lower edge of snow cover that appeared in each pixel for 20 days was taken as the snowline in the Altai Mountains. In summary, when extracting the snowline elevation in the three mountainous areas using the SCDR method, the threshold values were $74.2 \%, 76.5 \%$, and $83.3 \%$ for the Tianshan Mountains (overlaying data for 31 days), Kunlun Mountains (overlaying data for 34 days), Altai Mountains (overlaying data for 24 days), respectively.
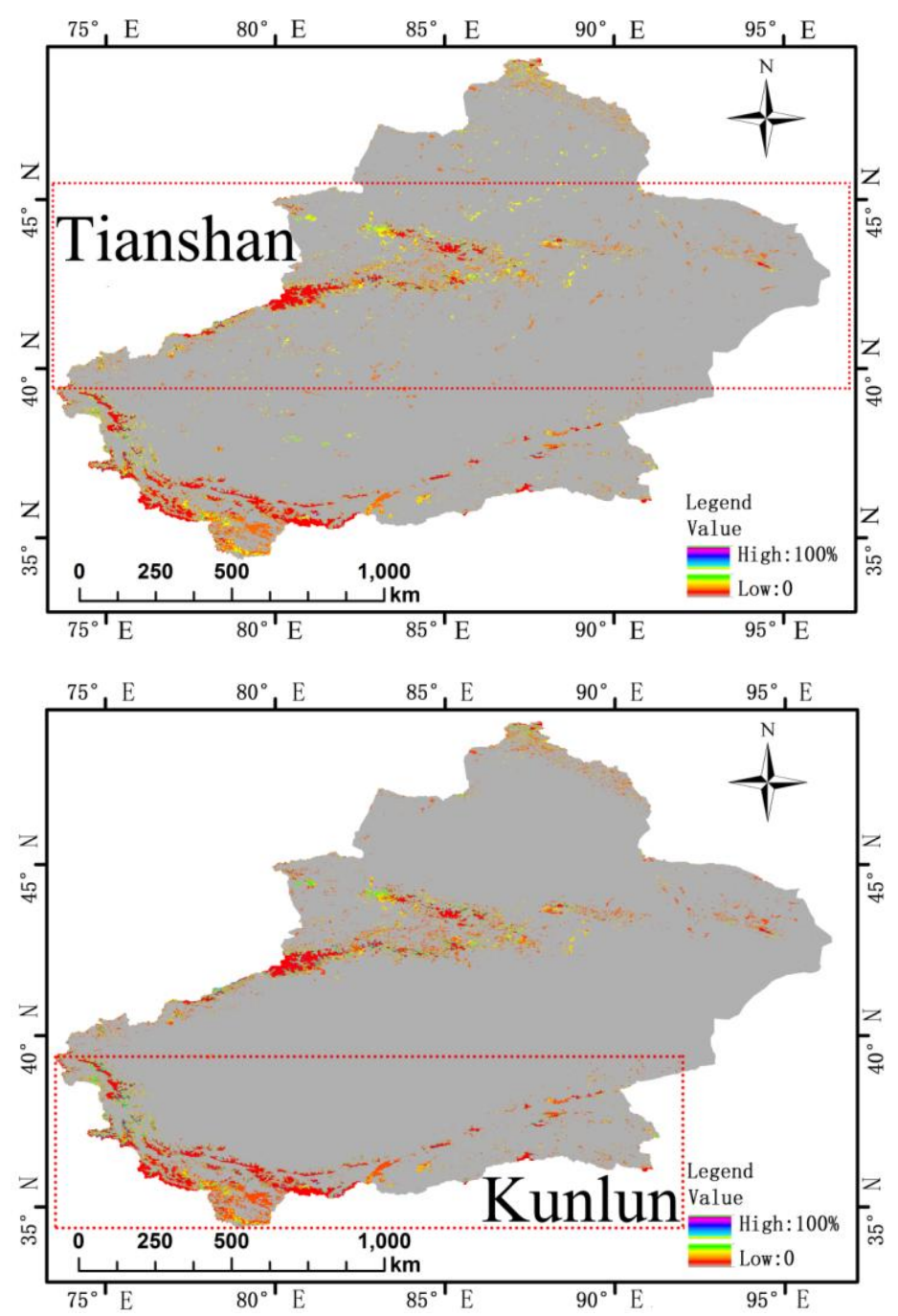


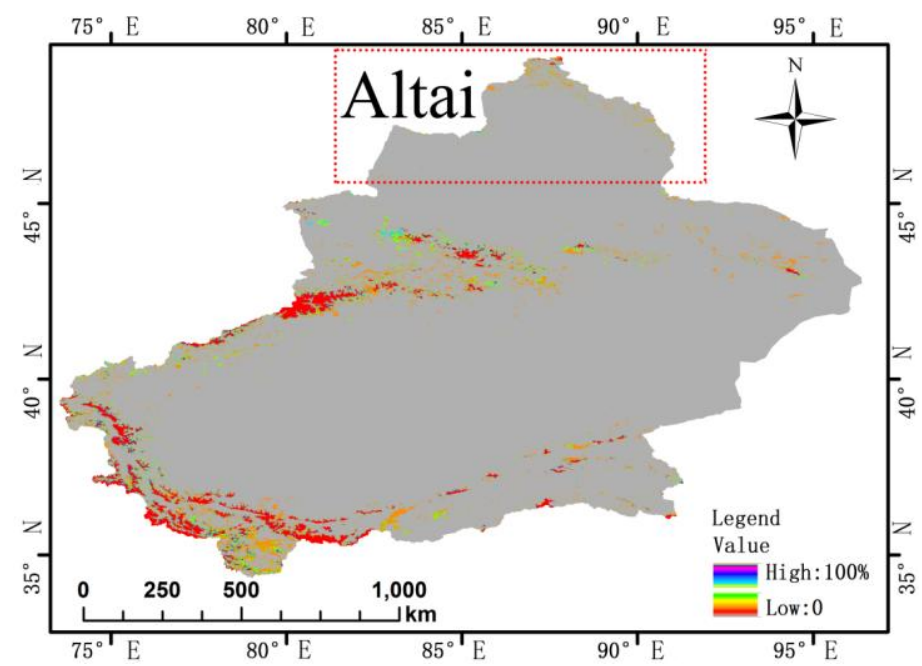

Figure 3. Overlaid maps of snow cover with different ratios for days 206-236 in the Tianshan Mountains (top), days 203-236 in the Kunlun Mountains (middle), and days 216-239 in the Altai Mountains (bottom), 2014
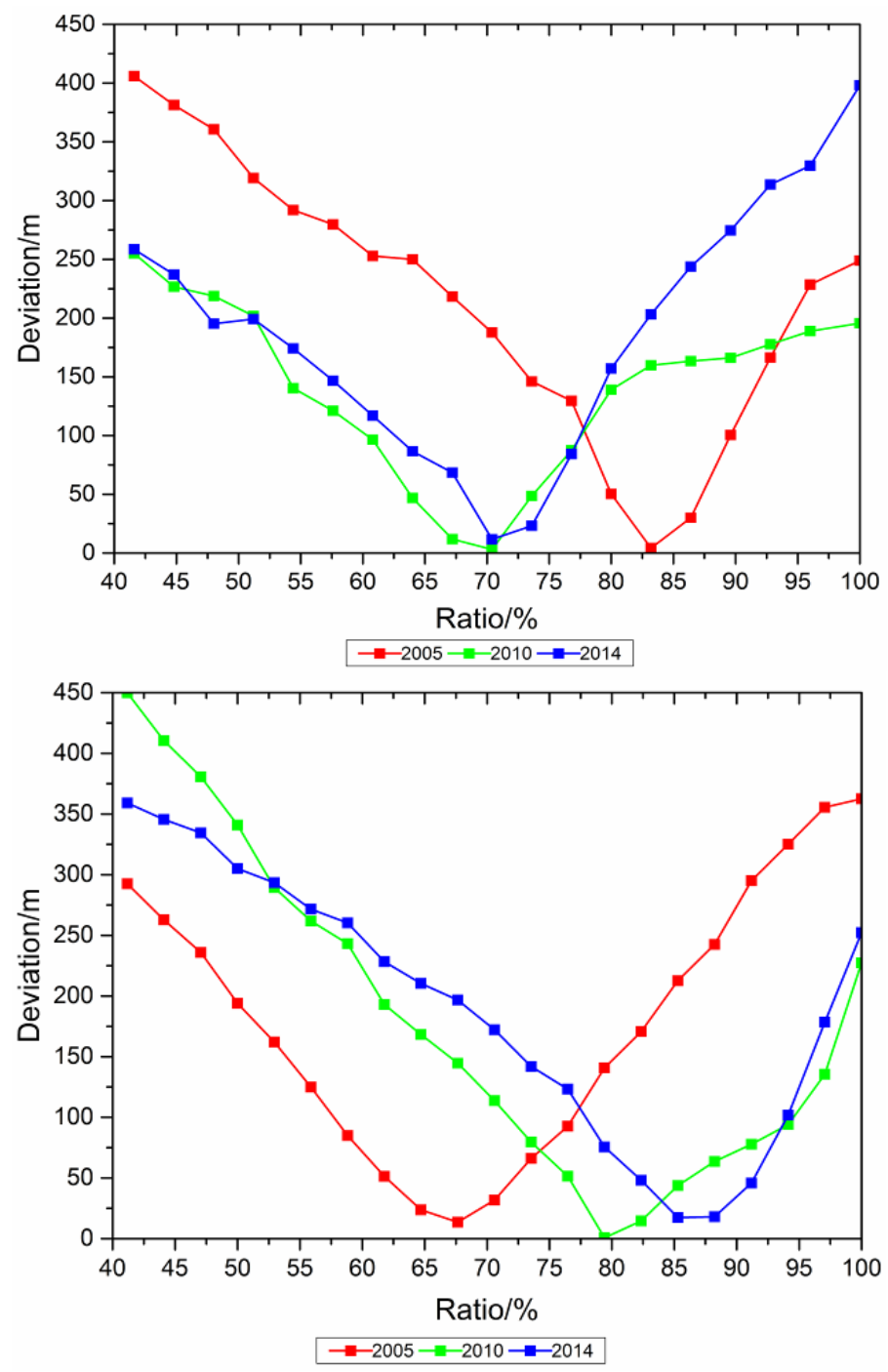

APPLIED ECOLOGY AND ENVIRONMENTAL RESEARCH 16(5):6281-6298. http://www.aloki.hu • ISSN 15891623 (Print) • ISSN 17850037 (Online) DOI: http://dx.doi.org/10.15666/aeer/1605_62816298 (c) 2018, ALÖKI Kft., Budapest, Hungary 


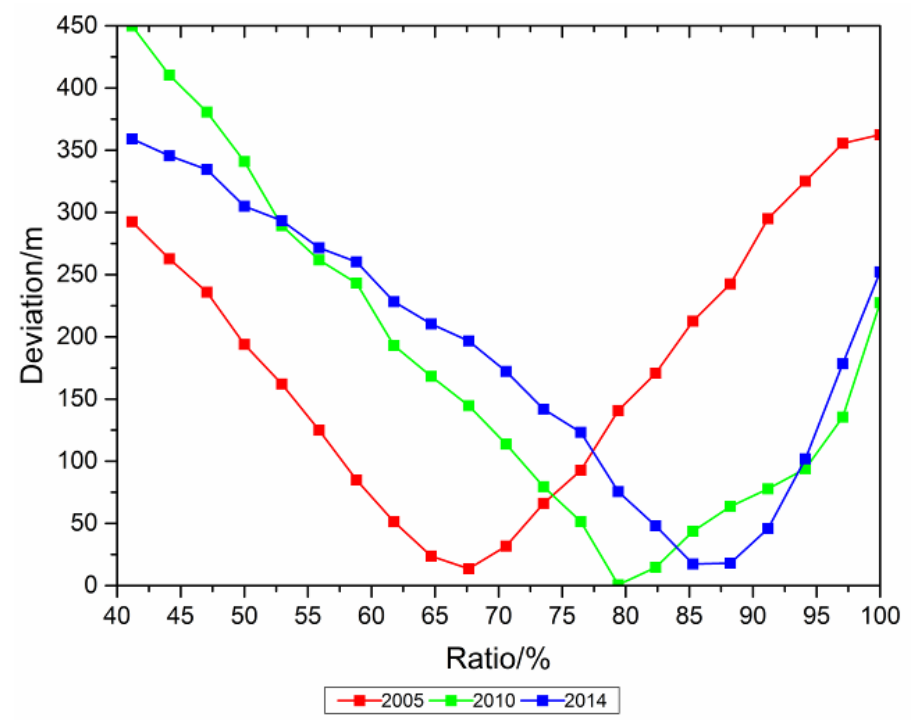

Figure 4. Deviation of snowline elevation with different ratios from "true value" in the Tianshan Mountains (top), Kunlun Mountains (middle), and Altai Mountains (bottom) over different years

\section{Accuracy evaluation of snowline}

(1) Accuracy evaluation of snow cover area

Local areas were selected from the three major mountainous areas in 2015 (Fig. 5). The evaluation was accomplished in different areas using the Kappa coefficient, based on the consistency between the snow cover area obtained using the SCDR method and the "true value" of snow cover area based on the MOD10A1/MYD10A1 snow cover classification map. Table 1 shows that the Kappa coefficients were 0.92, 0.82, and 0.87 for the Tianshan, Kunlun, and Altai mountains, respectively. A study (Klein and Barnett, 2003) has shown that with $0.81<$ Kappa $<1.00$, two images can be considered highly consistent. In summary, relatively high consistency was obtained with the "true value" when extracting the snow cover area, based on the MOD10A1/MYD10A1 daily snow cover image, using the SCDR method with thresholds of $74.2 \%, 76.5 \%$, and 83.3\% for the Tianshan Mountains (overlaying data for 31 days), Kunlun Mountains (overlaying data for 34 days), and Altai Mountains (overlaying data for 24 days), respectively.

Table 1. Kappa coefficients for snow cover area extracted using snow cover duration ratio method

\begin{tabular}{c|c|c|c}
\hline \multirow{2}{*}{} & Tianshan Mountains & Kunlun Mountains & Altai Mountains \\
\cline { 2 - 4 } & \multicolumn{2}{|c}{ Number of pixels with snow cover } \\
\hline Landsat-OLI & 4562 & 522 & 176 \\
MOYD10A1 & 4315 & 484 & 157 \\
Number of shared pixels & 4213 & 435 & 149 \\
Number of total pixels & 11775 & 2275 & 716 \\
Kappa coefficient & 0.92 & 0.82 & 0.87 \\
\hline
\end{tabular}



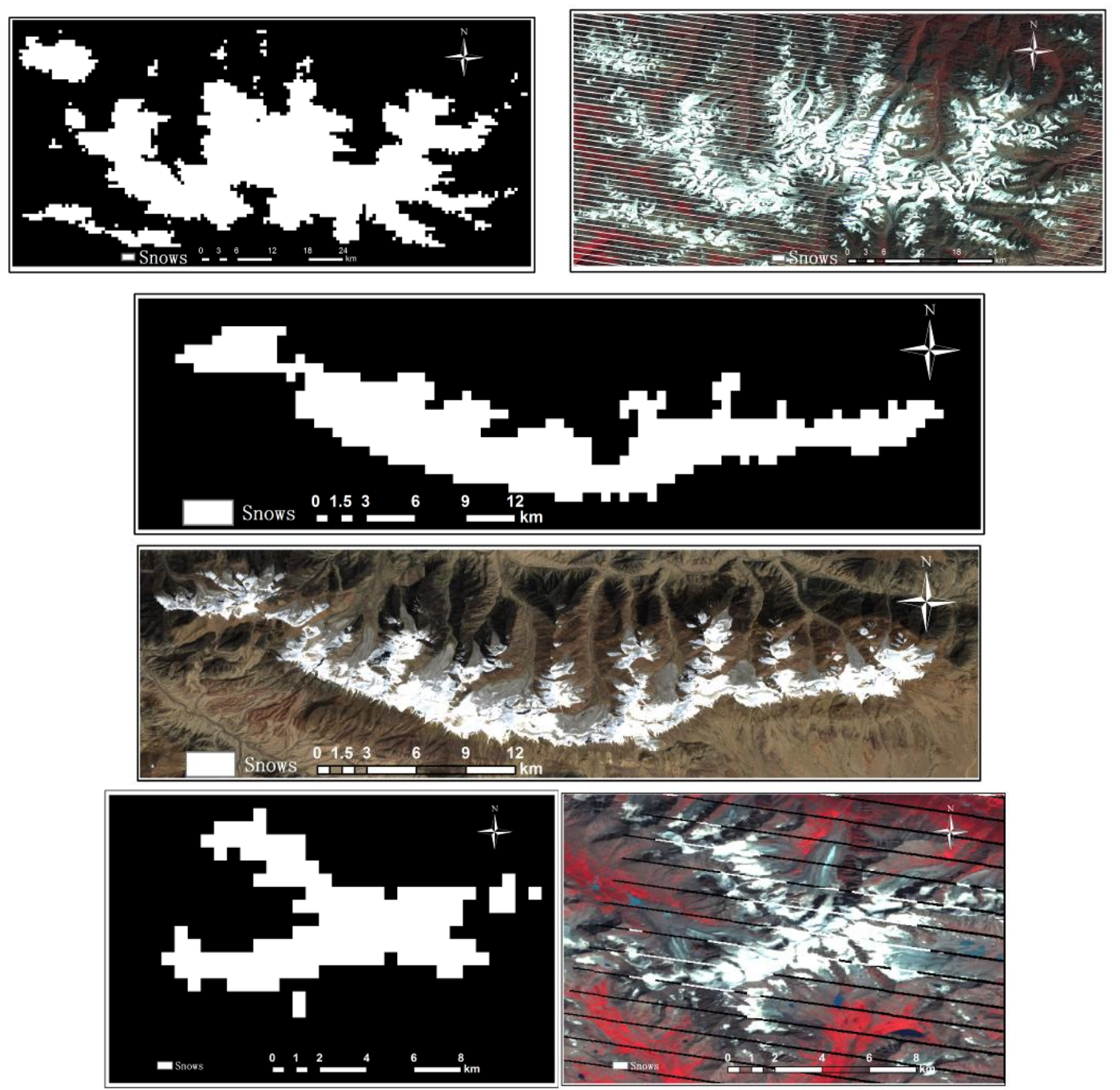

Figure 5. MOD1OA1/MYDIOA1 and Landsat-OLI snow cover maps in the same areas of the Tianshan Mountains (top), Kunlun Mountains (middle), and Altai Mountains (bottom)

(2) Accuracy evaluation of snowline elevation

Local areas were selected from the three major mountain areas of the Xinjiang region in 2015. The accuracy of snowline extracted using the SCDR method was analyzed statistically based on $\mathrm{Pa}, \mathrm{Pc}, \mathrm{Pb}, \mathrm{Pd}, \mathrm{RMSE}$, and the correlation with the "true value." As shown in Table 2, the value of $\mathrm{Pa}=-8.15 \mathrm{~m}$ for the Kunlun Mountains was the smallest, and the values for the Tianshan and Altai mountains were similar to each other (19.07 and $19.12 \mathrm{~m}$, respectively). The Tianshan Mountains ranked highest for Pc and $\mathrm{Pb}$ (93.13 and $-85.55 \mathrm{~m}$, respectively); the values for the Kunlun Mountains were 52.41 and $-70.38 \mathrm{~m}$, respectively, and those for the Altai Mountains were 71.67 and -53.92 $\mathrm{m}$, respectively. The Kunlun Mountains had the smallest value of $\mathrm{Pd}(61.81 \mathrm{~m})$, followed by the Altai Mountains $(65.88 \mathrm{~m})$ and the Tianshan Mountains $(90.63 \mathrm{~m})$. The RMSEs of the Altai and Kunlun mountains were similar to each other (77.01 and 76.32 $\mathrm{m}$, respectively), whereas that of the Tianshan Mountains was relatively large (97.93 $\mathrm{m})$. The above analysis shows that all the errors for the three mountain areas were within the range of $100 \mathrm{~m}$, meeting the accuracy requirement of the study. 
Table 2. Errors in snowline elevations obtained using the snow cover duration ratio method

\begin{tabular}{c|c|c|c|c|c}
\hline & $\begin{array}{c}\text { Mean error } \\
(\mathbf{P a}) / \mathbf{m}\end{array}$ & $\begin{array}{c}\text { Negative error } \\
(\mathbf{P b}) / \mathbf{m}\end{array}$ & $\begin{array}{c}\text { Positive error } \\
(\mathbf{P c}) / \mathbf{m}\end{array}$ & $\begin{array}{c}\text { Mean absolute } \\
\text { error }(\mathbf{P d}) / \mathbf{m}\end{array}$ & $\begin{array}{c}\text { Root mean square } \\
\text { error }(\mathbf{R M S E}) / \mathbf{m}\end{array}$ \\
\hline $\begin{array}{c}\text { Tianshan } \\
\text { Mountains }\end{array}$ & 19.07 & -85.55 & 93.13 & 90.63 & 97.93 \\
$\begin{array}{c}\text { Kunlun } \\
\text { Mountains } \\
\text { Altai }\end{array}$ & -8.15 & -70.38 & 52.41 & 61.81 & 76.32 \\
Mountains & 19.12 & -53.92 & 71.67 & 65.88 & 77.01 \\
\hline
\end{tabular}

Table 3 summarizes the average snowline elevations extracted using the SCDR method and the "true value," together with their correlation coefficients. The average snowline elevations for the Tianshan, Kunlun, and Altai mountains, extracted using the SCDR method, were 4030.12, 5458.15, and $3114.59 \mathrm{~m}$, respectively, whereas the "true value" snowlines were 4046.12, 5449.99, and $3133.71 \mathrm{~m}$, respectively. The correlation between the snowlines extracted using the SCDR method and the "true value" was highest for the Altai Mountains (0.943); the coefficients were 0.843 and 0.887 for Tianshan and Kunlun mountains, respectively. Table 4 shows that the correlation coefficients of snowline elevations extracted using the SCDR method and the "true value" ranged from 0.8 to 1.0 in the three mountain areas, indicating a relatively high degree of correlation. Figure 6 shows scatter plots of snowline elevation in the three mountain areas extracted using the SCDR method versus the "true value," which reflects their correlation with the "true value" more directly.

Table 3. Correlations between snowline elevation extracted using the snow cover duration ratio $(S C D R)$ method and the "true value"

\begin{tabular}{c|c|c|c}
\hline & $\begin{array}{c}\text { Average elevation of snowlines } \\
\text { extracted by SCDR/m }\end{array}$ & $\begin{array}{c}\text { Average elevation of } \\
\text { "true-value" snowlines/m }\end{array}$ & $\begin{array}{c}\text { Correlation } \\
\text { coefficient }\end{array}$ \\
\hline Tianshan Mountains & 4030.13 & 4046.12 & 0.843 \\
Kunlun Mountains & 5458.15 & 5449.99 & 0.887 \\
Altai Mountains & 3114.59 & 3133.71 & 0.943 \\
\hline
\end{tabular}

In summary, the SCDR method achieved high accuracy for snowline extraction in the Tianshan, Kunlun, and Altai mountains with thresholds of $74.2 \%, 76.5 \%$, and $83.3 \%$, respectively. This method was therefore considered suitable for extracting snowlines in the Xinjiang region.

Table 4. Degree of correlation for correlation coefficients

\begin{tabular}{c|c}
\hline Correlation coefficients & Degree of correlation \\
\hline $0.8<\mathrm{IrI}<1$ & High correlation \\
$0.5<\mathrm{IrI} \leq 0.8$ & Moderate correlation \\
$0.3<\mathrm{IrI} \leq 0.5$ & Low correlation \\
$0.8<\mathrm{IrI}<0.3$ & Extremely low correlation \\
\hline
\end{tabular}



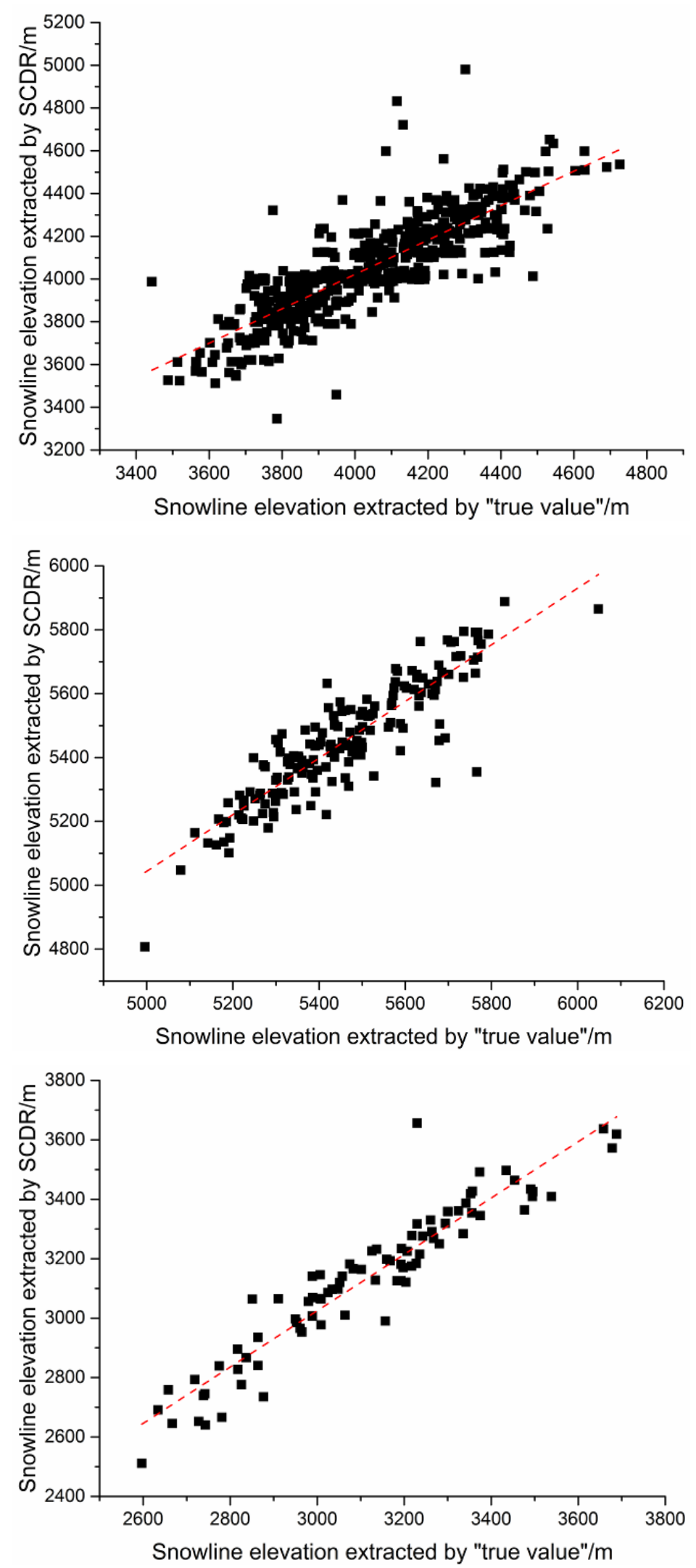

Figure 6. Scatter plots of snowline elevation extracted using the snow cover duration ratio (SCDR) method versus the "true value" in the Tianshan Mountains (top), Kunlun Mountains (middle), and Altai Mountains (bottom) 


\section{Dynamic variation characteristics of snowline in Xinjiang}

\section{Dynamic variation analysis of snowline elevation in the entire Xinjiang region}

Figure 7 shows that the variation of average snowline elevation in the Xinjiang (2001-2005) was within the range of $250 \mathrm{~m}$, while the snowline elevation was maintained at approximately $3950 \mathrm{~m}$. Through linear fitting (Table 5), we found that the average snowline elevation increased annually, with a tendency rate of 160.38 $\mathrm{m} /$ decade. The lowest average elevation occurred in $2001(3828.06 \mathrm{~m})$ and the highest occurred in $2015(4085.00 \mathrm{~m})$. Here, the result of snowline change in the middle of Qilian Mountains and Western Nyainqentanglha are compared with Zhao et al. (2015) and Zhang et al. (2016). Generally, the mean snowline elevation increases. Although the average elevation in Xinjiang, less than that inWestern Nyainqentanglha Range and the Middle of Qilian Mountains, the increase trend in Xinjiang is the fastest. The annually increasing snowline elevation in the Xinjiang region is a consequence of the considerable influence of global warming. A study has shown that global warming poses a profound threat to the ecological environment, and that it is the primary cause of the reductions of permafrost, snow cover area, and glaciers in China. The decrease of ice and the decline in snow cover area lead to the rise of snowline elevation.

Based on linear fitting, we found that the maximum snowline elevation had a weak downward trend, with a tendency rate of $25.14 \mathrm{~m} /$ decade. Conversely, the minimum snowline elevation showed a slow upward trend, with a tendency rate of $128.68 \mathrm{~m} /$ decade. Compared with the average annual snowline elevation in the Xinjiang region, the minimum and maximum snowline elevations have changed significantly, and the extents of their variations have been larger than the change in average snowline elevation. For different years, the maxima and minima snowline elevations have appeared in different locations within the study area. Compared with the Tibetan Plateau, the minimum snowline elevation is on the rise, but the maximum snowline elevation trend is the opposite. This is because of the vast area of the Xinjiang region and the complex distribution of topography. In addition to climatic factors that have affected the constant variation of minimum and maximum snowline elevations, localized topography, geomorphology, and occurrence of extreme disasters have also had an effect. In some marginal areas of the Xinjiang region with complex topography and geomorphology, even small variations of precipitation and temperature can cause an increase in disastrous weather events because of the impact of aspect, slope, or human factors. For example, were the temperature to increase sharply and precipitation to decrease during summer, the snowline elevation would show correspondingly large variation. This is why the minimum, maximum, and average snowline elevations varied with significant differences.

Table 5. Linear regression models between snowline elevation and time in different areas

\begin{tabular}{c|c}
\hline & Linear regression model \\
\hline Average snowline elevation in Xinjiang region & $\mathrm{y}=16.038 \mathrm{t}-28237$ \\
Maximum snowline elevation in Xinjiang region & $\mathrm{y}=-2.5143 \mathrm{t}+12221$ \\
Minimum snowline elevation in Xinjiang region & $\mathrm{y}=12.868 \mathrm{t}-23152$ \\
Average snowline elevation in Tianshan Mountains & $\mathrm{y}=27.563 \mathrm{t}-51659$ \\
Average snowline elevation in Kunlun Mountains & $\mathrm{y}=14.287 \mathrm{x}-23612$ \\
Average snowline elevation in Altai Mountains & $\mathrm{y}=5.5493 \mathrm{x}-7999$ \\
\hline
\end{tabular}




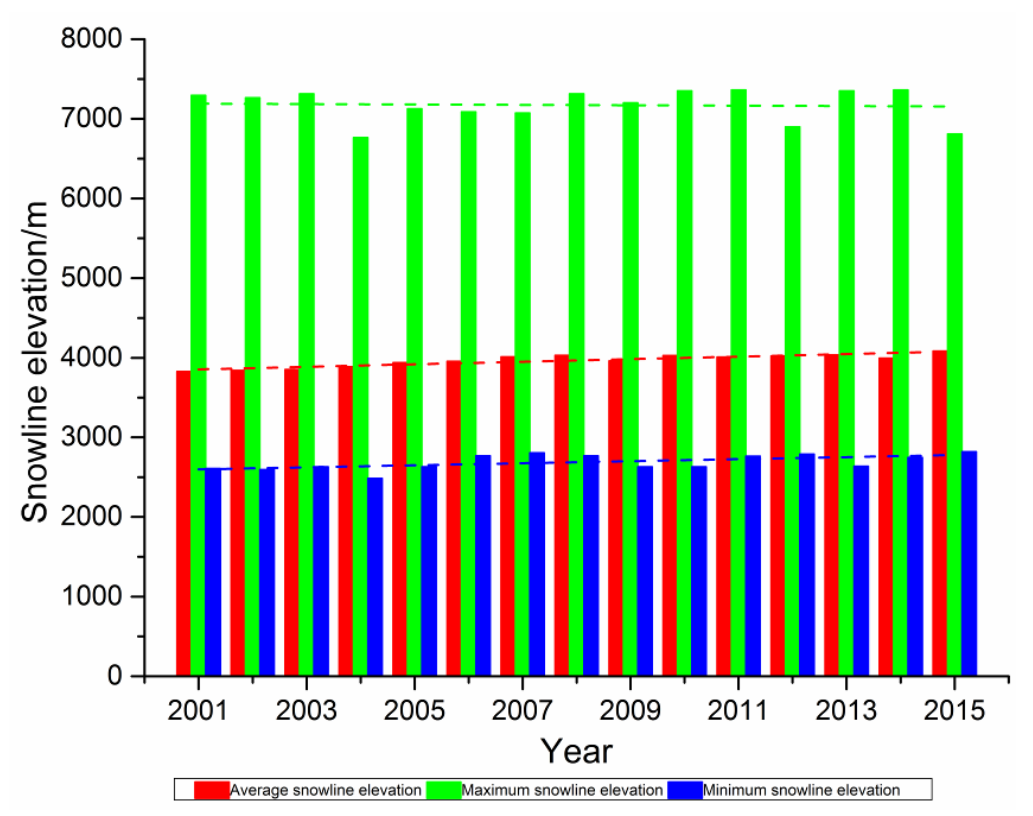

Figure 7. Dynamic variation of snow elevation in the Xinjiang region (2001-2015)

Comparative analysis of dynamic variation of snowline elevation in the three mountain areas

To study the dynamic variation of snowline elevation in the different mountain areas of the Xinjiang region, and with consideration of the spatial heterogeneity of the region, we divided the Xinjiang region into the three mountain areas (Kunlun, Tianshan, and Altai mountains) and analyzed their respective snowline elevations comparatively.

Figure 8 depicts fluctuating upward trends of snowline elevation in the Kunlun, Tianshan, and Altai mountains during 2001-2015, consistent with the trend of average snowline elevation across the entire Xinjiang region.

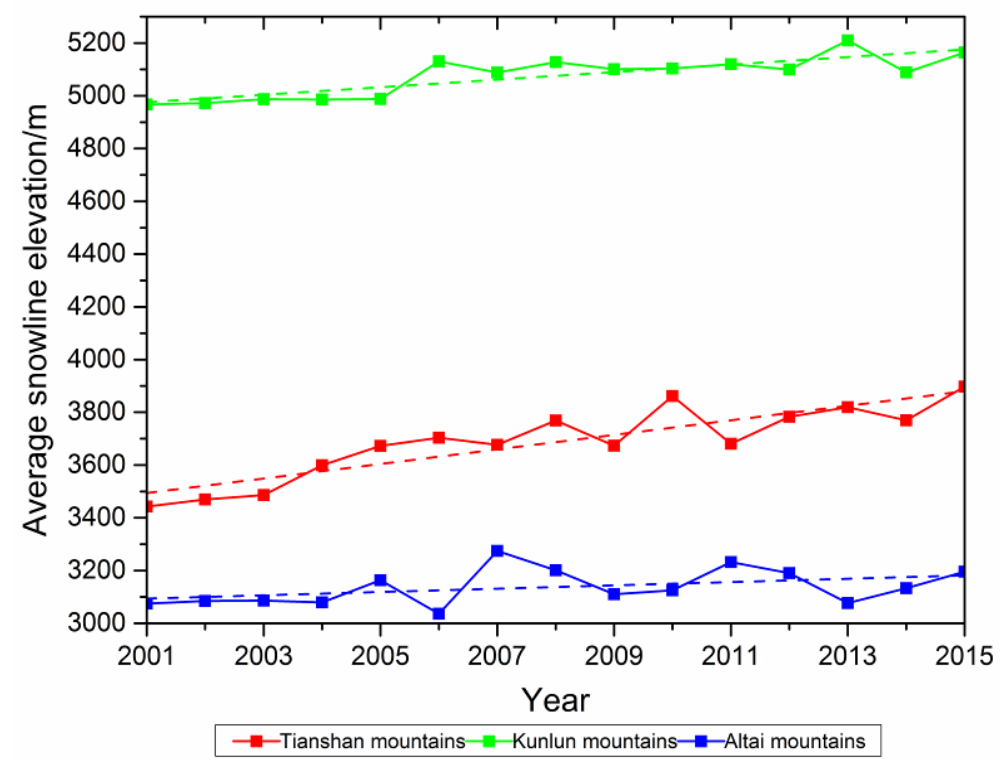

Figure 8. Dynamic variation of snowline elevation in the three mountain areas of the Xinjiang region (2001-2015) 
Figure 9 illustrates the dynamic variation of air temperature and precipitation in the three mountain areas. During 2001-2015, temperature showed an upward trend in all three areas, whereas precipitation showed a downward trend. The temperature rise and decline of precipitation led to the upward trend of snowline elevation in the three mountain areas. Table 5 shows that the tendency rates and amplitude fluctuations of snowline elevation were $142.87,275.63$, and $55.29 \mathrm{~m} /$ decade and 242.81, 454.65, and $200.34 \mathrm{~m}$ in the Kunlun Tianshan, and Altai mountains, respectively. The above analysis revealed upward trends of snowline elevation in the three mountain areas of the Xinjiang region during 2001-2015. The Altai Mountains showed the most stable variation of snowline elevation, followed by the Kunlun Mountains, and the Tianshan Mountains.
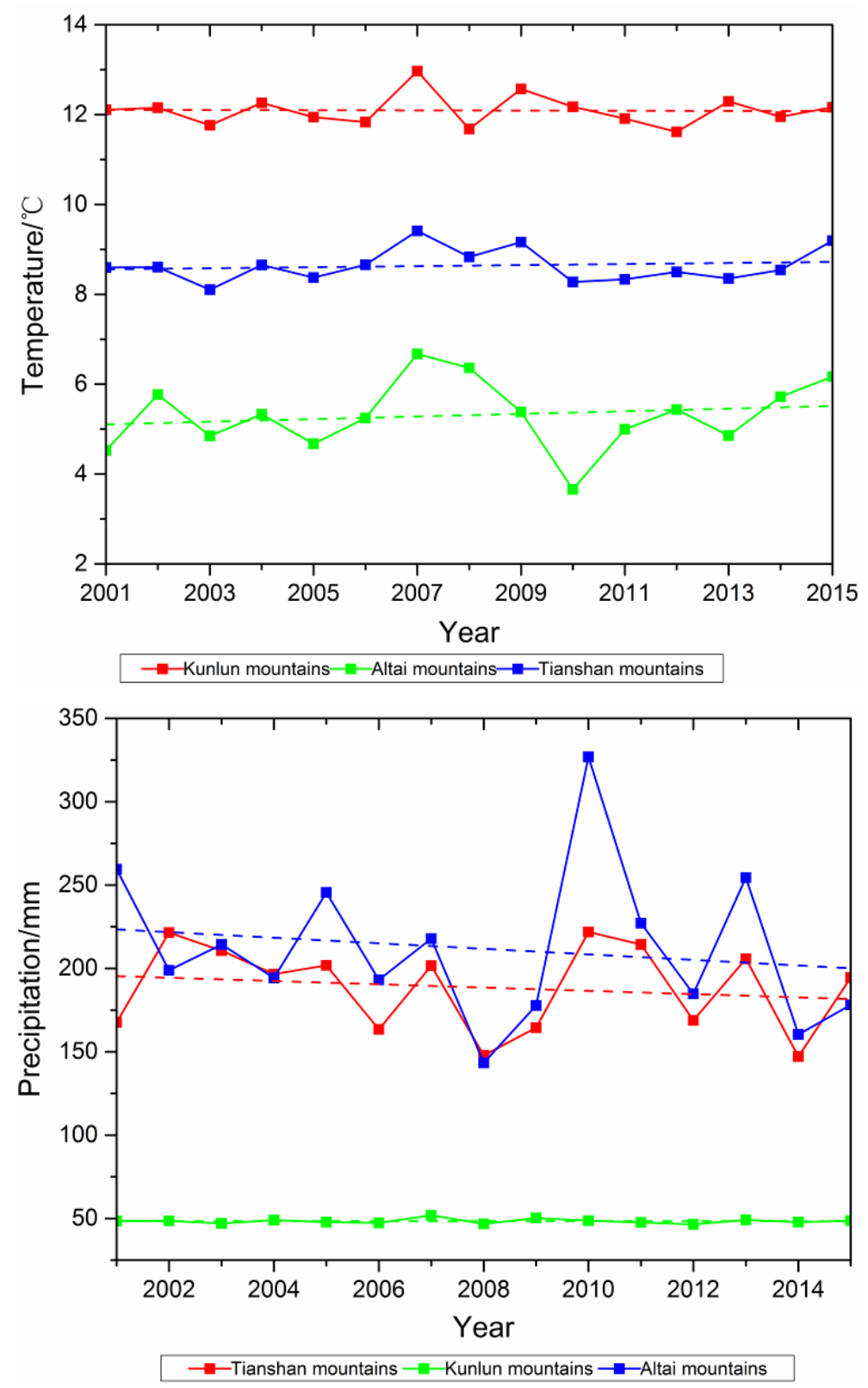

Figure 9. Variations of temperature (top) and precipitation (bottom) in the three mountain areas of the Xinjiang region (2001-2015) 
As shown by the distribution of average snowline elevation in the three mountain areas (2001-2015), the annual snowline elevation of the Kunlun Mountains was highest, followed by the Tianshan Mountains, and the Altai Mountains. This indicates that the snowline elevation decreased from south to north across the Xinjiang region, and that the distribution was characterized by longitudinal zonation. This is mainly because the Indian monsoon weakens as it passes across the Tibetan Plateau (with elevation of $5000 \mathrm{~m}$ ), and thus, it produces only small amounts of precipitation on the northern slopes of the Kunlun Mountains. Only a strong Pacific monsoon can reach the eastern edge of the Kunlun Mountains during June-August, which can produce some precipitation; however, its impact on the middle section of the Kunlun Mountains is weak. Additionally, the movement of moist air masses from the Atlantic Ocean is prevented by the Pamirs, and thus, they have little effect on the mid-section of the Kunlun Mountains. The southern section of the Tianshan Mountains is relatively sheltered, blocked by high mountain ranges that prevent access by Atlantic water vapour (Gao et al., 2010). Furthermore, this area faces China's largest desert (Taklimakan Desert) and thus, the effect of reduced atmospheric moisture results in decreased precipitation and high temperatures. However, the Ili River Valley is surrounded by mountains on three sides, which trap water vapor from the Atlantic Ocean, resulting in abundant precipitation and low temperatures on the windward slopes in this area. The Altai Mountains are located on the moist westerly windward side, making the area rich in precipitation, particularly solid precipitation in the winter. Figure 9 shows that the Kunlun Mountains had higher average annual temperature and much lower precipitation than the other two areas during 2001-2015. The highest precipitation and lowest temperature were found in the Altai Mountains every year. The above analysis showed that the snowline elevation decreased from south to north in the Xinjiang region and that the distribution was characterized by longitudinal zonation.

\section{Conclusions}

(1) For the SCDR method, the extracted snowline elevations passed the accuracy test and thus, the method was considered suitable for the Xinjiang region.

(2) During 2001-2015, the average snowline elevation remained at about $3950 \mathrm{~m}$ within a 250-m range of fluctuation. However, linear trend analysis revealed an annual increasing trend of average snowline elevation in the Xinjiang region, with a tendency rate of $160.38 \mathrm{~m} /$ decade. The minimum snowline elevation showed a fluctuating upward trend, while the maximum snowline elevation exhibited a weak downward trend. However, both the minimum and maximum snowline elevations showed larger fluctuations compared with the change of the average snowline elevation.

(3) Comparative analysis of different areas of the Xinjiang region revealed that the snowline elevation showed a fluctuating rising trend in the Kunlun, Tianshan, and Altai mountains during 2001-2015. Of the three areas, the Altai Mountains showed the most stable variation of snowline elevation, followed by the Kunlun Mountains, and the Tianshan Mountains.

(4) According to the distribution of snowline elevation in three mountain areas (2001-2015), the snowline elevation of the Kunlun Mountains in each year was the highest, followed by the Tianshan Mountains and the Altai Mountains. Thus, the snowline elevation has decreased from south to north in the Xinjiang region and its distribution is characterized by longitudinal zonation. 
Acknowledgements. This research was supported by the National Natural Science Foundation of China (41471358) and the National Science Foundation of China (41505077).

\section{REFERENCES}

[1] Brahmbhatt, R. M., Bahuguna, I., Rathore, B. P. et al. (2012): Variation of snowline and mass balance of glaciers of Warwan and Bhut Basins of Western Himalaya using remote sensing technique. - Journal of the Indian Society of Remote Sensing 40(4): 629-637.

[2] Deng, Y. W., Xie, Z. C., Qin, J. X. et al. (2006): The field equilibrium line altitude in the Ganga Yarlung Zangbo rivers system: Establishment and its environmental significance. - Journal of Glaciology and Geocryology 28(6): 865-872.

[3] Gao, P., Wei, W. S., Liu, M. Z. et al. (2010): Snow density and Liquid water content within the seasonal snow cover in the Western Tianshan mountains. - Journal of Glaciology and Geocryology 32(4): 786-790.

[4] Hantel, M., Maurer, C. (2011): The median winter snowline in the Alps. Meteorologische Zeitschrift 20(3): 267-276.

[5] Jiang, F. C., Wu, X. H., Wang, S. B. et al. (2004): Features of space distribution of the forest line and relations between the forest line and climatic limit of permafrost and climatic snowline in china. - Journal of Geomechanics 10(4): 289-298.

[6] Jiang, Z. X. (1987): Trend surface analysis of the existent snowline in west China. Scientia Geographica Sinica 7(1): 1-8.

[7] Klein, A.-G., Barnett, A. C. (2003): Validation of daily MODIS snow cover maps of the Upper Rio Grande River Basin for the 2000-2001 snow year. - Remote Sensing of Environment 86(2): 162-176.

[8] Li, G. H., Wang, C., Xi, X. H. et al. (2013): Extraction of glacier snowline based on airborne LiDAR and hyperspectral data fusion. - Remote Sensing for Land \& Resources 29(3): 79-84.

[9] Liu, J., Chen, R., Wang, G. (2015): Snowline and snow cover monitoring at high spatial resolution in a mountainous river basin based on a time-lapse camera at a daily scale. Journal of Mountain Science 12(1): 60-69.

[10] Lu, Z., Liu, Z. H., Yan, Y. (2007): Features of snowmelt flood and control measures in Xinjiang. - Research of Soil and Water Conservation 14(6): 216-219.

[11] McFadden, E. M., Ramage, J., Rodbell, D. T. (2011): Landsat TM and ETM+ derived snowline altitudes in the Cordillera Huayhuash and Cordillera Raura. - The Cryosphere 5(2): 419-430.

[12] Nie, N., Zhang, Z. J., Zhang, W. C. et al. (2013): Analysis of the characteristics of the glacier system and typical glacier change based on remote sensing in the Yarlung Zangbo River basin during the past 30 years. - Journal of Glaciology and Geocryology 35(3): 541-552.

[13] Sa, C. L., Liu, G. X., Bao, G. et al. (2013): Spatial-temporal changes of snow cover in Xinjiang in recent 10 years. - Science of Surveying and Mapping 38(1): 72-74.

[14] Tang, X. N., Yan, X. L., Ni, M. J. et al. (2012): Changes of the snow cover days on Tibet Plateau in last 40 years. - Acta Geographica Sinica 67(7): 951-959.

[15] Wang, L. P., Xie, Z. C., Ding, L. F. et al. (2010): Establishing the field of equilibrium line altitude of the glacier system in the Chiangtang Plateau based on geographic information system and its distribution characteristics. - Arid Land Geography 33(5): 692-702.

[16] Wang, X., Xie, Z. S., Feng, Q. H. (2003): The calculated ELA and its distribution characteristics of the glacier system in the Tarim River basin. - Journal of Glaciology and Geocryology 25(4): 380-388.

[17] Wang, Z. Y., Che, T. (2012): Validation and assessment of cloud obscuration reduction of snow cover products in arid areas in China. - Arid Zone Research 29(2): 312-315. 
[18] Xiao, F., Du, Y., Ling, F. et al. (2010): Digital extraction of snowline based on flow path analysis. - Journal of Remote Sensing 14(1): 62-67.

[19] Yu, H., Feng, Q. S., Zhang, X. T. et al. (2009): An approach for monitoring snow depth based on AMSR-E data in the pastoral area of Northern Xinjiang. - Acta Prataculturae Sinica 18(4): 210-216.

[20] Zhang, L. C., Hu, L. Q., Li, S. et al. (2015a): GIS-Based analysis on the snowline distributional characteristics of south and North slopes of Tianshan mountain and their influencing factors. - Research of Soil and Water Conservation 22(3): 259-263.

[21] Zhang, L. C., Hu, L. Q., Li, S. et al. (2015b): Contrastive analysis based on remote sensing image snow line elevation extraction method-on the north slope of Tianshan Mountains as an example. - Arid Land Geography 38(4): 788-796.

[22] Zhang, Q. B., Kang, S. C., Zhang, G. S. (2016): Changes of snow line altitude for glaciers on Western Nyainqentanglha range observed by remote sensing. - Scientia Geographica Sinica 36(2): 1937-1943.

[23] Zhang, Y., Huang, X. D., Wang, W. et al. (2013): Validation and algorithm redevelopment of MODIS daily fractional snow cover products. - Arid Zone Research 30(5): 808-814.

[24] Zhao, J., Huang, Y. S., Shi, Y. F. et al. (2015): Relationship between snow line change and climate change in the middle of Qilian Mountains during 2000-2012. - Mountain Research 33(3): 683-689. 